\title{
Impact of Comorbidities on Disease Activity, Patient Global Assessment, and Function in Psoriatic Arthritis: A Cross-Sectional Study
}

\author{
Ennio Lubrano (D) - Silvia Scriffignano - Ana Belen Azuaga • \\ Julio Ramirez $\cdot$ Juan D. Cañete $\cdot$ Fabio Massimo Perrotta
}

Received: July 22, 2020 / Published online: August 17, 2020

(C) The Author(s) 2020

\section{ABSTRACT}

Introduction: The aim of this study was to evaluate the impact of comorbidities on disease activity, patient's impact of the disease, patient global assessment, and function in psoriatic arthritis (PsA).

Methods: Consecutive PsA patients were enrolled in this cross-sectional study. During the visit, the patients underwent a complete physical examination and clinical/laboratory data were collected, including type and number of comorbidities, recorded as simple comorbidity count (SCC).Disease activity was assessed using the Disease Activity Score for Psoriatic Arthritis (DAPSA) and the Minimal Disease Activity (MDA) was also evaluated. The Psoriatic Arthritis Impact of Disease (PsAID), the Health Assessment Questionnaire-Disability Index (HAQ-DI), and the Patient Global Assessment of disease activity (PtGA) were also collected.

Digital Features: To view digital features for this article go to https://doi.org/10.6084/m9.figshare.12777581.

E. Lubrano $(\bowtie) \cdot S$. Scriffignano · F. M. Perrotta Academic Rheumatology Unit, Dipartimento Di Medicina E Scienze, Della Salute "Vincenzo Tiberio", Università Degli Studi del Molise, Campobasso, Italy e-mail: enniolubrano@hotmail.com

A. B. Azuaga · J. Ramirez · J. D. Cañete Arthritis Unit, Rheumatology Department, Hospital Clinic and IDIBAPS, Barcelona, Spain
Results: A total of 144 patients were enrolled. At least one comorbidity was registered in 104 (72.2\%) patients. The SCC was associated with DAPSA $(\beta=1.48, p=0.013)$, PsAID $(\beta=0.41$, $p<0.01)$, HAQ-DI $(\beta=0.11, p<0.01)$ and PtGA $(\beta=0.50, p<0.01)$. The comorbidities that showed an impact on outcome measures were anxiety and fibromyalgia (FM). Anxiety showed an impact on DAPSA $(\beta=14.46$, $p<0.001)$, PsAID $(\beta=1.98, p=0.039)$ and HAQ-DI $(\beta=0.54, p=0.036)$. FM showed an impact on DAPSA $(\beta=6.46, p=0.025)$, PsAID $(\beta=2.88, \quad p<0.001), \quad$ HAQ-DI $\quad(\beta=0.70$, $p<0.001), \quad$ PtGA $(\beta=2.00, \quad p=0.014)$, and MDA $(\beta=-2.79, p=0.01)$. The median PtGA value was different among patients with different numbers of comorbidities.

Conclusions: This study showed that comorbidities, either as a simple comorbidity count number or as single comorbidity, might have an impact on the main domains affecting PsA patients in real clinical practice.

Keywords: Comorbidities; Composite indices; Function; Outcome; Patient global assessment; Psoriatic arthritis 


\section{Key Summary Points}

Psoriatic Arthritis (PSA) is frequently associated with comorbidities that could affect the disease outcome.

While it is well recognized which are the most prevalent comorbidities in PsA, less is known about the impact that these comorbidities can have on different disease domains.

Our study showed that comorbidities impact some disease domains, such as disease activity, patient's impact, function, and quality of life.

The data provided give the possibility to the rheumatologist to globally assess the disease activity, estimating the weight of comorbidities on treatment decisions in treat to target (T2T) strategy, randomized clinical trials (RCTs), and even in routine clinical care.

\section{INTRODUCTION}

Psoriatic arthritis (PsA) is a chronic, inflammatory, and complex condition, occurring in approximately $15-30 \%$ of patients with psoriasis (PsO) [1, 2]. Initially, PsA has been considered a mild disease, while now it is unanimously recognized that PsA can lead to impaired function and reduced quality of life [1]. Recently, the term psoriatic syndrome was suggested for the identification of this condition through a different vision, in which the various musculoskeletal domains are involved (peripheral joints, dactylitis, axial, enthesitis), as well as the skin manifestations, including nails, that together represent a disease process [3].

Beyond the musculoskeletal and skin involvement, PsA is associated with extra-articular manifestations and comorbidities that might increase the burden of the disease $[4,5]$. PsA, together with the broad group of spondyloarthritis, is frequently associated with comorbidities and, based on some studies, more than half of PsA patients were affected by at least one comorbidity [6-8]. While it is well recognized which conditions are the most prevalent associated with PsA, including cardiovascular disease, obesity, metabolic syndrome, depression, anxiety, fibromyalgia (FM), and osteoporosis (OP) $[6,8,9]$, less is known about the impact that these comorbidities can have on different disease domains. In fact, the presence of a comorbidity might have a role at different levels $[10,11]$, and, recently, a multinational study showed that a high life impact, assessed by Psoriatic Arthritis Impact of Disease (PsAID) $\geq 4$, was associated with comorbidities [12]. Moreover, quality of life (QoL) is a domain that can be influenced by comorbidities [13], and also a functional impairment has been observed in PsA patients [14]. However, comorbidities may also play a negative role in the achievement of conditions such as remission or low disease activity and some reports have shown this data without defining the exact "weight" of them on composite indexes validated for PsA, such as Disease Activity Score for Psoriatic Arthritis (DAPSA) [15]. In other diseases, such as rheumatoid arthritis (RA), the achievement of a treatment goal, such as remission, decreased by $28 \%$ per additional morbidity, 1 year after the disease-modifying anti-rheumatic drugs (DMARDs) initiation. These results were in keeping with the role played by the Patient Global Assessment of disease activity (PtGA) in the final score of composite indexes developed and tailored for RA, such as Disease Activity Score 28 and the Clinical Disease Activity Index. In fact, some authors found an almost linear increase of PtGA with increasing number of comorbidities per patients, independently of RA disease activity $[16,17]$. Another condition, frequently co-existent in PsA patients, such as FM, can significantly and negatively influence the achievement of treatment targets, and still represent an unmet need [18].

At present, few studies have contemplated the assessment of the impact of comorbidities on disease activity measured by composite indexes validated in PsA. This aspect could be of some importance for the treatment strategy, 
namely treat to target (T2T) or randomized clinical trials (RCTs). Therefore, the aim of the present study was to evaluate the impact of comorbidities, either as a simple comorbidity count number or as single comorbidity, on disease activity, as well as on patient's impact of the disease, patient global assessment, and function in patients with PsA.

\section{METHODS}

\section{Patient Selection}

For this cross-sectional study, PsA patients were consecutively enrolled from January 1, 2019 until September 30, 2019, both at the Rheumatology Unit, Department of Medicine and Health Science, University of Molise (Italy) and at Servicio de Reumatología-Hospital Clínic de Barcelona (Spain). PsA patients, on at least 6-month follow-up treatment with conventional and/or biologic DMARDs, were considered potentially eligible for the study.

Inclusion criteria were:

1) PsA satisfying the ClASsification criteria for Psoriatic ARthritis (CASPAR) [19];

2) age $\geq 18$ years;

3) at least 6 months of follow-up at the study visit (patients had to have been treated for at least 6 months in our centers).

All procedures performed in studies involving human participants were in accordance with the ethical standards of the institutional and/or national research committee and with the 1964 Helsinki Declaration and its later amendments or comparable ethical standards. Informed consent was obtained from all individual participants included in the study. The study was approved by the Institutional Review Board of the University of Molise (protocol n. 0001-09-2017).

\section{Data Collection}

A detailed medical history and physical examination were performed in all patients. Demographics and disease characteristics, including gender, age, disease duration, level of education, and pattern of articular manifestations were collected. Laboratory parameters, including C-reactive protein (CRP) were also evaluated. The clinical assessment encompassed the number of tender and swollen joints (out of the 68/66 assessed joints), enthesitis, and dactylitis. Enthesitis was assessed by using the Leeds Enthesitis Index (LEI) [20], and dactylitis as present/absent, as published elsewhere [21, 22]. Skin assessment was performed using the body surface area (BSA). The Health Assessment Questionnaire-Disability Index (HAQ-DI) [23], PtGA and pain assessment on numerical rating scale $(0-10 \mathrm{~cm})$ were performed by all patients. Physician's global evaluation of disease activity on a visual analogue scale (VAS) $(0-10 \mathrm{~cm})$ was also recorded [24].

The type of comorbidity was recorded and a simple comorbidity count (SCC) was performed, assessing for each patient the number of coexisting comorbidities. In particular, cardiovascular diseases, hypertension, dyslipidemia, obesity, diabetes, anxiety/depression, FM, OP, osteoarthritis, and other comorbidities were recorded for this study and they are routinely imputed in our datasets. We evaluated the presence of FM by using the 2010 American College of Rheumatology criteria and the presence of osteoarthritis on clinical examination and on past medical history.

\section{Disease Activity Indices and Minimal Disease Activity (DAPSA, MDA)}

DAPSA score was calculated by adding the number of tender and swollen joints, pain, PtGA, and CRP (mg/dl) [25].

Minimal disease activity (MDA) was defined according to Coates et al. [26]. Patients were considered in MDA when they satisfied 5/7 of the following criteria: tender joint count $\leq 1$; swollen joint count $\leq 1$; BSA $\leq 3 \%$; patient pain score of $\leq 15$; PtGA of $\leq 20$; HAQ-DI $\leq 0.5$; and tender entheseal points $\leq 1$. 


\section{Function and Impact of Disease Indices (HAQ-DI, PsAID)}

The HAQ-DI and the PsAID were evaluated as measures of function and impact of the disease. In particular, the 12-Item version of the PSAID was used [27]. HAQ-DI $\leq 0.5$ defined a good functional status and PsAID $\leq 4$ a low impact of disease.

\section{Statistical Analysis}

Statistical analysis was performed using R software (version 3.6.2). Normally distributed variables were summarized using the mean \pm standard deviation (SD), non-normally distributed variables by the median and interquartile range (IQR), or minimum and maximum value (min/max). A simple (linear and logistic) regression analysis was performed to analyze the association between DAPSA, PsAID, HAQ-DI, PtGA, MDA, and comorbidities. To investigate the burden of each comorbidity on the different outcome measures, a multiple (linear and logistic) regression analysis was carried out. A stepwise approach based on the Akaike Information Criterion (AIC) was used to define the optimal set of variables to retain in each model, minimizing the AIC value. The independent variables were represented by the specific comorbidity found and adjusted by age, sex, disease duration, and BSA. All categorical variables included in the multiple linear/logistic analysis were evaluated as a dummy one. Goodness of fit was estimated using the residual standard error (RSE), multiple- $R^{2}$, and adjusted$R^{2}\left(\mathrm{Ad}-R^{2}\right)$. Odds ratio (OR) and confidence interval (CI) 95\% were calculated where appropriate. The one-way ANOVA was applied to compare PtGA across patients with different numbers of comorbidities. Multiple comparisons between the six groups extracted from SCC were also performed using the Bonferroni correction. The residual homoskedasticity was evaluated using Bartlett's test. A $p<0.05$ value was deemed statistically significant.

\section{RESULTS}

A total of 144 PsA patients, satisfying the CASPAR criteria were consecutively enrolled. Patient demographics and disease characteristics are summarized in Table 1.

Of the studied population, $92(63.8 \%)$ were male, the mean $(\mathrm{SD})$ age was $56.6( \pm 13.4)$ years and the median (IQR range) disease duration was 10 (4.5-17) years. DAPSA median (IQR range) was 8.4 (4.3-16), PsAID median was 2.2 (0.8-4), HAQ-DI median was $0.25(0-0.75)$, and PtGA median was 3 (2-6). The patients that satisfied MDA 5/7 criteria were 75 (52\%). The comorbidities were reported, and the presence of at least one comorbidity was registered in 104 $(72.2 \%)$ patients. To list them, the SCC was used, and the median value of this variable was 1 (min/max: 0-5). DAPSA, PsAID, HAQ-DI, MDA, and PtGA were considered the outcome variables in the simple regression analysis (liner and logistic), where SCC was the independent factor. For each outcome variable, a multiple regression model (linear and logistic) was also performed to assess which comorbidity could have a higher impact on them.

\section{Comorbidities' Impact on DAPSA}

When DAPSA was evaluated in a single linear regression model, a statistically significant association was found with the SCC $(\beta=1.48$, $p=0.013$, RSE $\left.=8.66, R^{2}=0.04\right)($ Table 2$)$.

This data suggests that the number of comorbidities have an impact on DAPSA: when there is an increase of one comorbidity, DAPSA score increases by a mean of 1.48 points. When a multiple linear regression model was carried out, anxiety $(\beta=14.46, \quad p<0.001), \quad \mathrm{FM}$ $(\beta=6.46, \quad p=0.025), \quad$ and OP $\quad(\beta=9.26$, $p=0.02$ ) showed an impact on DAPSA. The indices to evaluate the goodness of fit of this model were: $\mathrm{RSE}=7.75$, Ad- $R^{2}=0.2$ (F-statistic $=7.70, p$ value $<0.001)($ Table 3$)$.

These results seem to show that either the increasing number of comorbidities have an impact on DAPSA score or the type of comorbidity can play a role on this composite index. 
Table 1 Demographic, clinical characteristics, and disease activity of the 144 PsA enrolled patients

Female/male, $n$

Mean age (SD), years

BMI, median (IQR)

Disease duration, median (IQR), years

Tender joints, median (IQR)

Swollen joints, median (IQR)

BSA \%, median (IQR)

Enthesitis (LEI), median (IQR)

CRP, mg/l, median (IQR)

MDA $5 / 7, n,(\%)$

DAPSA median (IQR)

HAQ-DI, median (IQR)

PsAID, median (IQR)

PtGA, median (IQR), cm

Comorbidities

SCC, median (min-max)

Patient with at least 1 comorbidity $n,(\%)$

Benign prostatic hypertrophy, $n$, (\%)

Obesity, $n,(\%)$

Diabetes, $n$, (\%)

Hypertension, $n$, (\%)

Metabolic syndrome, $n$, (\%)

Dyslipidemia, $n$, (\%)

Fibromyalgia, $n$, (\%)

Hypothyroidism, $n$, (\%)

Chronic kidney disease, $n$, (\%)

Osteoarthritis, $n$, (\%)

Anxiety, $n$, (\%)

Osteoporosis, $n,(\%)$
$52 / 92$

$56.6( \pm 13.4)$

$26.8(23.1-29.3)$

$10(4.5-17)$

1 (0-2)

$1(0-1)$

$1(0-4)$

$0(0-0)$

4 (2-6)

$75(52)$

$8.4(4.3-16)$

$0.25(0-0.75)$

$2.2(0.8-4)$

3 (2-6)

$1(0-5)$

$104(72)$

$26(28.2)$

$37(25.7)$

28 (19.4)

$25(17.3)$

20 (13.9)

19 (13.2)

$10(6.9)$

$10(6.9)$

$8(5.5)$

5 (3.4)

$4(3)$

$4(3)$

$P s A$ psoriatic arthritis, $B M I$ body mass index, $B S A$ body surface area, $L E I$ Leeds Enthesitis Index, $C R P C$-reactive protein, $M D A$ minimal disease activity, DAPSA Disease Activity score for PSoriatic Arthritis, HAQ-DI Health Assessment Questionnaire-Disability Index, PsAID Psoriatic Arthritis Impact of Disease, PtGA Patient's Global Assessment, SCC simple comorbidity count, $S D$ standard deviation, $I Q R$ interquartile range 
Table 2 Association of DAPSA, PsAID, HAQ-DI, and PtGA with SCC by simple linear regression analysis

\begin{tabular}{llcc}
\hline Outcome variables & Coefficient regression (IC 95\%) & $\boldsymbol{p}$ value & $\boldsymbol{R}^{\mathbf{2}}$ \\
\hline DAPSA & $1.48(0.31-2.65)$ & 0.013 & 0.04 \\
PsAID & $0.41(0.12-0.70)$ & $<0.01$ & 0.06 \\
HAQ-DI & $0.11(0.04-0.18)$ & $<0.01$ & 0.07 \\
PtGA & $0.50(0.11-0.80)$ & $<0.01$ & 0.06 \\
MDA & $-0.06(0.72-1.21)$ & 0.61 & - \\
\hline
\end{tabular}

Association of MDA with SCC by simple logistic regression analysis

$D A P S A$ Disease Activity score for PSoriatic Arthritis, Ps $A I D$ Psoriatic Arthritis Impact of Disease, $H A Q-D I$ Health Assessment Questionnaire-Disability Index, $P t G A$ patient's global assessment, $M D A$ minimal disease activity

\section{Comorbidities' Impact on PsAID}

A single linear regression analysis was used to search any potential change of PsAID in PsA patient with comorbidities. In this analysis the association between PSAID and SCC showed a $\beta=0.41 \quad\left(p<0.01, \quad \mathrm{RSE}=2.14, \quad R^{2}=0.06\right)$ (Table 2). These data suggest that the number of comorbidities has an impact on PsAID: when there is an increase of one comorbidity, the PsAID score increases by a mean of 0.41 points. Multiple linear regression model was also applied to investigate which comorbidity could have an impact on this index. The best model selected showed that anxiety $(\beta=1.98$, $p=0.039)$ and FM $(\beta=2.88, p<0.001)$ were the comorbidities having a significant impact on PsAID. This model showed a RSE $=1.84$ and Ad- $R^{2}=0.28$ (F-statistic: 9.58, $p$ value $<0.001$ ) As for the DAPSA, also for PsAID, the presence of comorbidities, assessed as SCC or type of comorbidity, showed an impact on the perception of the disease in our group of PsA patients.

\section{Comorbidities' Impact on HAQ-DI}

In a single linear regression analysis, the association between HAQ-DI and SCC showed $\beta=0.11 \quad\left(p<0.01, \quad \mathrm{RSE}=0.53, \quad R^{2}=0.07\right)$ (Table 2). These data suggest that the number of comorbidities has an impact on HAQ-DI: when there is an increase of one comorbidity, the HAQ-DI score increases by a mean of 0.11 points. In a multiple linear regression analysis, all comorbidities were considered as independent variables, showing that anxiety $(\beta=0.54$, $p=0.036)$, FM $(\beta=0.70, p<0.001)$, and OP $(0.76, p<0.01)$, had a significant impact on function. This model had a RSE $=0.499$ and an Ad- $R^{2}=0.19$,

(F-statistic $=5.54$, $p$ value $<0.001$ ) (Table 3 ). The presence of comorbidities like FM and anxiety, due to their potential intrinsic "functional" nature, could strongly impact function, independently by age and disease duration.

\section{Comorbidities' Impact on PtGA}

In a single linear regression model, an association between PtGA and SCC ( $\beta=0.50, p<0.01$, RSE $=2.4, R^{2}=0.06$ ) was found (Table 2 ). These data suggest that the number of comorbidities has an impact on PtGA: when there is an increase of one comorbidity, PtGA score increases by a mean of 0.5 . A multiple linear regression analysis was performed considering all comorbidities. In this model, FM and OP showed to have a significant impact on PtGA, respectively $\beta=2.00(p=0.014)$ and $\beta=3.00$ $(p=0.017)$. This model had a RSE $=2.44$ and Ad- $R^{2}=0.06 \quad$ (F-statistic: 4.38, $p<0.01$ ) (Table 3). Moreover, the median PtGA value was different among patients with different numbers of comorbidities when evaluated in a oneway ANOVA model. This test showed an Fvalue $=3.66 \quad(F \quad$ critical $\quad$ value $=2.21) \quad$ and $p=0.003$ (Fig. 1). 
Table 3 Multiple linear regression analysis of DAPSA, PsAID, HAQ-DI, and PtGA with the type of comorbidity, adjusted for age, sex, disease duration, and BSA

\begin{tabular}{|c|c|c|c|c|}
\hline \multicolumn{5}{|c|}{ Coefficient (SE), ( $p$ value) } \\
\hline Independent variables & DAPSA & PsAID & HAQ-DI & PtGA \\
\hline \multirow[t]{2}{*}{ Anxiety } & 14.46 & 1.98 & 0.54 & - \\
\hline & $(3.97),(<0.001)$ & $(0.36),(0.039)$ & $(0.07),(0.036)$ & \\
\hline \multirow[t]{2}{*}{ Disease duration } & 0.15 & 0.04 & - & - \\
\hline & $(0.06),(0.024)$ & $(0.01),(0.01)$ & & \\
\hline \multirow[t]{2}{*}{ Hypertension } & - & 0.70 & - & - \\
\hline & & $(0.47),(0.13)$ & & \\
\hline \multirow[t]{2}{*}{ BSA } & 0.48 & - & - & - \\
\hline & $(0.17),(0.005)$ & & & \\
\hline \multirow[t]{2}{*}{ Fibromyalgia } & 6.46 & 2.88 & 0.70 & 2.00 \\
\hline & $(2.85),(0.025)$ & $(0.72),(<0.001)$ & $(0.18),(<0.001)$ & $(0.80),(0.014)$ \\
\hline \multirow[t]{2}{*}{ Diabetes } & - & - & 0.16 & - \\
\hline & & & (0.11), (0.17) & \\
\hline \multirow[t]{2}{*}{ Hypothyroidism } & - & - & - & 1.30 \\
\hline & & & & $(0.80),(0.1)$ \\
\hline \multirow[t]{2}{*}{ Osteoporosis } & 9.26 & - & 0.76 & 3.00 \\
\hline & $(4.21),(0.02)$ & & $(0.27),(<0.01)$ & $(1.24),(0.017)$ \\
\hline \multirow[t]{4}{*}{ Dyslipidemia } & - & - & 0.21 & - \\
\hline & & & $(0.14),(0.12)$ & \\
\hline & Ad- $\mathrm{R}^{2}=0.2$ & Ad- $\mathrm{R}^{2}=0.28$ & $\mathrm{Ad}-\mathrm{R}^{2}=0.19$ & $\mathrm{Ad}-R^{2}=0.06$ \\
\hline & $P$ value $<0.001$ & $P$ value $<0.001$ & $P$ value $<0.001$ & $P$ value $<0.01$ \\
\hline
\end{tabular}

For each outcome variables, the independent variables included in best selected model on AIC were showed $D A P S A$ Disease Activity score for PSoriatic Arthritis, BSA body surface area, PsAID Psoriatic Arthritis Impact of Disease; HAQ-DI Health Assessment Questionnaire-Disability Index; $P t G A$ patient's global assessment; $M D A$ minimal disease activity, $S E$ standard error, $A d-R^{2}$ adjusted- $\mathrm{R}^{2}$

These data reinforce the concept that comorbidities have an impact of the global assessment of the disease judged by patients.

\section{Comorbidities' Impact on MDA}

In a simple logistic regression analysis, no statistically significant association between MDA and SCC was found $(\beta=-0.06, p=0.61)$
(Table 2). However, a multiple logistic regression analysis was also performed. The best selected model showed that in those PsA patients with FM, there was a statistically significant probability that MDA was not achieved, showing a negative impact in reaching an MDA status $(\beta=-2.79, p=0.01)$. The $\mathrm{OR}$, calculated with this model, showed a statistically significance for $\mathrm{FM}: \quad \mathrm{OR}=6.1 \mathrm{e}^{-2} \quad(\mathrm{CI} \quad 95 \%$ 


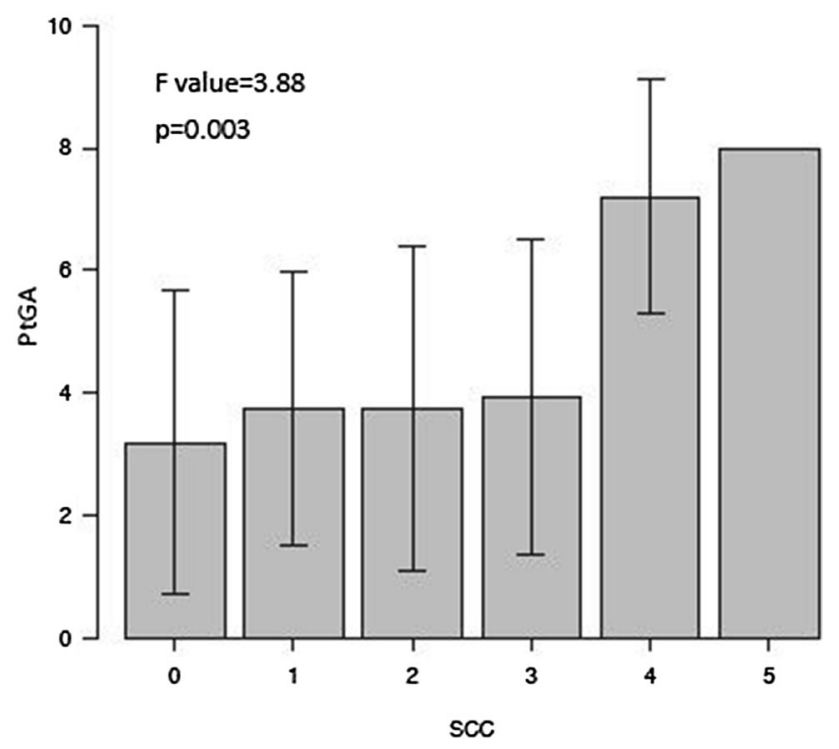

Fig. 1 One-way ANOVA analysis of PtGA and SCC. The median PtGA value was different among patients with different numbers of comorbidities, and was statistically significant. Bar graph, PtGA value in PsA patient divided

$-0.006 /-0.609 ; p$ value $=0.024)$. These results showed that MDA, differently from the other "continuous" instruments and for its intrinsic construction as outcome measure, seems not to be influenced by the comorbidities number but, among the comorbidities, it is probably more affected by FM.

\section{DISCUSSION}

The present study was aimed to assess the impact of comorbidities in a group of PsA patients. The results showed that there is an impact on some disease domains, such as disease activity, patient's impact, function, and quality of life. These results are not a novelty because it is well recognized that comorbidities play a role in PsA. However, a possible novelty was the evaluation of the impact on a composite index validated and tailored for PsA, such as DAPSA [25]. In our results, when there is an increase of one comorbidity, the DAPSA score increases by a mean of 1.48 points. These data could have some practical implications, giving the possibility to the rheumatologist to globally assess the disease activity. In fact, like in our in six group, considering the comorbidities number. $P t G A$ patient's global assessment, SSC simple comorbidities count

group of patients in follow-up and in a condition of good clinical control of the disease activity, estimating the weight of comorbidities on the final score could be important for treatment decisions in T2T strategy, RCTs, and even in routine clinical care [18]. Moreover, the impact of comorbidities in the assessment of disease activity could also be useful for other practical aspects, such as the adherence of therapy, which is still an unmet need in how it would be predicted and the potential role of coexistent diseases $[28,29]$. In our previous study, we demonstrated in PsA patients that the presence at baseline of comorbidities was, together with high disease activity and severe skin involvement, the factors that led us to a T2T strategy with tight control in routine clinical care, showing how the impact of comorbidities should carefully be taken into account [11]. Our results also showed that comorbidities have an influence either as a comorbidity count (number of comorbidities present at time of observation) or as single type of comorbidity. With regard to the latter point, FM seems to be one of the most frequent comorbidities having an impact on PsA, in our group, as well as anxiety. These two conditions were statistically 
associated with all domains evaluated as outcome and this is in keeping with data coming from a systematic review of literature [4]. As an interesting aspect, this review showed that the prevalence and impact of medical comorbidity on patient-reported outcomes (PROs) were very high in patients with PsA, while no data were found on the impact of comorbidity on composite indices. However, our results confirmed that FM and anxiety should be considered in the management of PsA patients for their potential impact, trying to identify these two as multi-morbidities more than comorbidities [5]. In fact, FM could be considered the prototype of multi-morbid disease in which the management and treatment focus on the patient and effectiveness is quantified by overall indicators such as quality of life or physical function [5, 30]. Furthermore, in clinical practice, anxiety and FM, as non-inflammatory aspects of PsA, may lead to high disease outcome measures and they might be factors leading to unnecessary antiinflammatory or immunosuppressive therapy. Therefore, in clinical practice, we have to differentiate which aspects of the disease (skin involvement and/or arthritis) are responsible for the high disease activity score.

Our results are in keeping with other studies, in which some domains such as function (assessed by HAQ-DI), patient's impact (assessed by PsAID), and quality of life were affected by the presence of comorbidities [12, 31, 32]. Our study comes from two centers devoted to the management and treatment of PsA and the patients enrolled were, generally, in a condition of low disease activity. These data could be a potential selection bias, but we believe that these types of patients are what we regularly see and treat in our clinic. In other words, the impact that we have observed from the comorbidities, calculated as comorbidity count or as a single type of comorbidity, might be considered the "real" impact when the acute phases of inflammation are controlled. The fact that we showed how much the DAPSA score, for instance, can increase of mean 1.48 points could be of some importance for treatment strategies in patients already treated and followed up.
The study has some strengths and limitations. It was design as a cross-sectional one on methodological aspects and not on the prevalence of comorbidities in PsA. Therefore, we decided to evaluate the comorbidities as a simple count instead of some indices and regardless of the specific role of them. In particular, with regard to the SCC, we decided to adopt this instrument because our main aim was to measure the impact of any comorbidities on these outcome measures, regardless any specific instrument that, possibly, could select only specific comorbidities. In fact, we believe that to evaluate the real role of some specific comorbidities, such as cardiovascular and/or metabolic, a longitudinal study will be necessary to provide data on these co-existent diseases in PsA.

\section{CONCLUSIONS}

In conclusion, comorbidities may play a role in terms of impact on disease activity, measured by validated composite indices, as well as on patient's impact, patient's global assessment of the disease, function, and quality of life, by using validated PROs. This should be considered in routine clinical care, as well in T2T strategy, and longitudinal observational studies could provide more data on this intriguing management aspect of PsA patients.

\section{ACKNOWLEDGEMENTS}

We thank the participants of the study.

Funding No funding or sponsorship was received for this study or publication of this article. All authors had full access to all of the data in this study and take complete responsibility for the integrity of the data and accuracy of the data analysis.

Authorship All named authors meet the International Committee of Medical Journal Editors (ICMJE) criteria for authorship for this article, take responsibility for the integrity of 
the work as a whole, and have given their approval for this version to be published.

Authorship Contributions All authors should have made substantial contributions to all of these sections: conception and design of the study, acquisition of data, analysis and interpretation of data, drafting the article, revising it critically for important intellectual content, and final approval of the version to be submitted.

Disclosures Ennio Lubrano, Silvia Scriffignano, Ana Belen Azuaga, Julio Ramirez, Juan D. Cañete, and Fabio Massimo Perrotta have nothing to disclose.

Compliance with Ethics Guidelines All procedures performed in studies involving human participants were in accordance with the ethical standards of the institutional and/or national research committee and with the 1964 Helsinki Declaration and its later amendments or comparable ethical standards. Informed consent was obtained from all individual participants included in the study. The study was approved by the Institutional Review Board of the University of Molise.

Data Availability The datasets generated during and/or analyzed during the current study are not publicly available but are available from the corresponding author on reasonable request.

Open Access. This article is licensed under a Creative Commons Attribution-NonCommercial 4.0 International License, which permits any non-commercial use, sharing, adaptation, distribution and reproduction in any medium or format, as long as you give appropriate credit to the original author(s) and the source, provide a link to the Creative Commons licence, and indicate if changes were made. The images or other third party material in this article are included in the article's Creative Commons licence, unless indicated otherwise in a credit line to the material. If material is not included in the article's Creative Commons licence and your intended use is not permitted by statutory regulation or exceeds the permitted use, you will need to obtain permission directly from the copyright holder. To view a copy of this licence, visit http://creativecommons.org/licenses/by$\mathrm{nc} / 4.0 /$.

\section{REFERENCES}

1. Ritchlin CT, Colbert RA, Gladman DD. Psoriatic arthritis. N Engl J Med. 2017;376:957-70. https:// doi.org/10.1056/NEJMra1505557.

2. Villani AP, Rouzaud M, Sevrain M, et al. Prevalence of undiagnosed psoriatic arthritis among psoriasis patients: systematic review and meta-analysis. J Am Acad Dermatol. 2015;73:242-8. https://doi.org/10. 1016/j.jaad.2015.05.001.

3. Lubrano E, Scriffignano S, Perrotta FM. Psoriatic arthritis, psoriatic disease, or psoriatic syndrome? J Rheumatol. 2019;46:1428-30. https://doi.org/10. 3899/jrheum.190054.

4. Cañete JD, Tasende JAP, Laserna FJR, Castro SG, Queiro R. The impact of comorbidity on patientreported outcomes in psoriatic arthritis: a systematic literature review. Rheumatol Ther. 2020. https://doi.org/10.1007/s40744-020-00202-x(Epub ahead of print).

5. Lubrano E, Scriffignano S, Perrotta FM (2020) Multimorbidity and comorbidity in psoriatic arthritisa perspective. Exp Rev Clin Immunol, article in press.

6. Scriffignano S, Perrotta FM, De Socio A, Lubrano E. Role of comorbidities in spondyloarthritis including psoriatic arthritis. Clin Rheumatol. 2019;38: 3-10. https://doi.org/10.1007/s10067-018-4332-7.

7. Husni ME. Comorbidities in psoriatic arthritis. Rheum Dis Clin North Am. 2015;41:677-98.

8. Molto A, Etcheto A, van der Heijde D, et al. Prevalence of comorbidities and evaluation of their screening in spondyloarthritis: results of the international cross-sectional ASAS-COMOSPA study. Ann Rheum Dis. 2016;75:1016-23.

9. Queiro R, Canete JD. Impact of cardiovascular risk factors on the achievement of therapeutic goals in psoriatic arthritis: is there any association? Clin Rheumatol. 2018;37:661-6. https://doi.org/10. 1007/s10067-018-4004-7.

10. Molto A, Dougados M. Comorbidities in spondyloarthritis including psoriatic arthritis. Best Pract Res Clin Rheumatol. 2018;32:390-400. https://doi. org/10.1016/j.berh.2018.09002. 
11. Lubrano E, Scriffignano S, De Socio A, Perrotta FM. Analysis of potential determinants for a treat-totarget strategy in psoriatic arthritis patients from a real-world setting. Clin Exp Rheumatol. 2019;37: 512.

12. Orbai AM, Perin J, Gorlier C. Determinants of patient-reported psoriatic arthritis impact of disease: an analysis of the association with gender in 458 patients from 14 countries. Arthritis Care Res (Hoboken). 2019. https://doi.org/10.1002/acr. 24090[Epub ahead of print].

13. Bavière W, Deprez X, Houvenagel E, et al. Association between comorbidities and quality of life in psoriatic arthritis: results from a multicentric crosssectional study. J Rheumatol. 2020;47:369-76. https://doi.org/10.3899/jrheum.181471.

14. Husted JA, Thavaneswaran A, Chandran V, Gladman DD. Incremental effects of comorbidity on quality of life in patients with psoriatic arthritis. J Rheumatol. 2013;40:1349-56. https://doi.org/10. 3899/jrheum.121500.

15. Eder L, Thavaneswaran A, Chandran V, Cook RJ, Gladman DD. Obesity is associated with a lower probability of achieving sustained minimal disease activity state among patients with psoriatic arthritis. Ann Rheum Dis. 2015;74:813-7. https://doi.org/ 10.1136/annrheumdis-2013-204448.

16. Radner H, Yoshida $\mathrm{K}$, Frits $\mathrm{M}$, et al. The impact of multimorbidity status on treatment response in rheumatoid arthritis patients initiating diseasemodifying anti-rheumatic drugs. Rheumatology (Oxford). 2015;54:2076-84. https://doi.org/10. 1093/rheumatology/kev239.

17. Radner H, Yoshida K, Hmamouchi I, Dougados M, Smolen JS, Solomon DH. Treatment patterns of multimorbid patients with rheumatoid arthritis: results from an international cross-sectional study. J Rheumatol. 2015;42:1099-104. https://doi.org/10. 3899/jrheum.141534.

18. Winthrop KL, Weinblatt ME, Bathon J. Unmet need in rheumatology: reports from the Targeted Therapies Meeting 2019. Ann Rheum Dis. 2020;79:88-93. https://doi.org/10.1136/annrheumdis-2019216151(Epub 2019 Oct 29).

19. Taylor W, Gladman D, Helliwell P, CASPAR Study Group, et al. Classification criteria for psoriatic arthritis: development of new criteria from a large international study. Arthritis Rheum. 2006;54: 2665-733. https://doi.org/10.1002/art.21972.

20. Healy PJ, Helliwell PS. Measuring clinical enthesitis in psoriatic arthritis: assessment of existing measures and development of an instrument specific to psoriatic arthritis. Arthritis Rheum. 2008;59: 686-91. https://doi.org/10.1002/art.23568.

21. Lubrano E, Perrotta FM, Scriffignano S, et al. Sustained very low disease activity and remission in psoriatic arthritis patients. Rheumatol Ther. 2019;6: 521-8. https://doi.org/10.1007/s40744-019-00171w.

22. Lubrano E, Scriffignano S, Azuaga AB, Ramirez J, Canete J, Perrotta FM. Assessment of the Patient Acceptable Symptom State (PASS) in psoriatic arthritis: association with disease activity and quality of life indices. RMD Open. 2020;6(1): e001170. https://doi.org/10.1136/rmdopen-2020001170 .

23. Ranza R, Marchesoni A, Calori G, et al. The Italian version of the functional disability index of the health assessment questionnaire. a reliable instrument for multicenter studies on rheumatoid arthritis. Clin Exp Rheumatol. 1993;11:123-8.

24. Lubrano E, Perrotta FM, Parsons WJ, et al. Patient's global assessment as an outcome measure for psoriatic arthritis in clinical practice: a surrogate for measuring low disease activity? J Rheumatol. 2015;42:2332-8. https://doi.org/10.3899/jrheum. 150595 .

25. Schoels MM, Aletaha D, Alasti F, et al. Disease activity in psoriatic arthritis (PsA): defining remission and treatment success using the DAPSA score. Ann Rheum Dis. 2016;75:811-8. https://doi.org/10. 1136/annrheumdis-2015-207507.

26. Coates LC, Fransen J, Helliwel PS. Defining disease activity in psoriatic arthritis: a proposed objective target for treatment. Ann Rheum Dis. 2010;69: 48-53. https://doi.org/10.1136/ard.2008.102053.

27. Gossec L, de Wit M, Kiltz U, EULAR PsAID Taskforce, et al. A patient-derived and patient-reported outcome measure for assessing psoriatic arthritis: elaboration and preliminary validation of the Psoriatic Arthritis Impact of Disease (PsAID) questionnaire, a 13-country EULAR initiative. Ann Rheum Dis. 2014;73:1012-9. https://doi.org/10.1136/ annrheumdis-2014-205207.

28. Gottlieb A, Gratacos J, Dikranian A, et al. Treatment patterns, unmet need, and impact on patient-reported outcomes of psoriatic arthritis in the United States and Europe. Rheumatol Int. 2019;39:121-30. https://doi.org/10.1007/s00296-018-4195-x.

29. Smolen JS, Gladman D, McNeil HP, et al. Predicting adherence to therapy in rheumatoid arthritis, psoriatic arthritis or ankylosing spondylitis: a large cross-sectional study. RMD Open. 2019;5:e000585. https://doi.org/10.1136/rmdopen-2017-000585. 
30. Radner H, Yoshida K, Smolen JS, Solomon DH. Multimorbidity and rheumatic conditions-enhancing the concept of comorbidity. Nat Rev Rheumatol. 2014;10:252-6. https://doi.org/10.1038/ nrrheum.2013.212.

31. Gorlier C, Orbai AM, Puyraimond-Zemmour D, et al. Comparing patient-perceived and physicianperceived remission and low disease activity in psoriatic arthritis: an analysis of 410 patients from 14 countries. Ann Rheum Dis. 2019;78:201-8. https://doi.org/10.1136/annrheumdis-2018214140.

32. Perrotta FM, Delle Sedie A, Scriffignano S, et al. Remission, low disease activity and improvement of pain and function in psoriatic arthritis patients treated with IL-12/23 and IL-17inhibitors. A multicenter prospective study. Reumatismo. 2020;72: 52-9. https://doi.org/10.4081/reumatismo.2020. 